Journal of Social Sciences 2 (2): 61-67, 2006

ISSN 1549-3652

(C) 2006 Science Publications

\title{
Quality Of Work Life: Implications Of Career Dimensions
}

\author{
${ }^{1}$ Raduan Che Rose, ${ }^{2}$ LooSee Beh, ${ }^{3}$ Jegak Uli and ${ }^{3}$ Khairuddin Idris \\ ${ }^{1}$ Graduate School of Management, Universiti Putra Malaysia, Malaysia \\ ${ }^{2}$ Faculty of Economics and Administration, Department of Administrative Studies and Politics \\ University of Malaya, Malaysia \\ ${ }^{3}$ Faculty of Educational Studies, Department of Professional Development and Continuing Education \\ Universiti Putra Malaysia, Malaysia
}

\begin{abstract}
Literature on QWL is limited and several studies commonly correlates with job satisfaction but no study on QWL has associated with career related factors. This empirical study was done to predict QWL in relation to career-related dimensions. The sample consists of 475 managers from the free trade zones in Malaysia for both the multinational corporations (MNCs) and the small-medium industries (SMIs). The result indicates that three exogenous variables are significant: career satisfaction, career achievement and career balance, with $63 \%$ of the variance in QWL.
\end{abstract}

Key words: Quality of work life (QWL), career, organizational climate

\section{INTRODUCTION}

Quality of Work Life (QWL) is a philosophy, a set of principles, which holds that people are the most important resource in the organization as they are trustworthy, responsible and capable of making valuable contribution and they should be treated with dignity and respect ${ }^{[1]}$. The elements that are relevant to an individual's quality of work life include the task, the physical work environment, social environment within the organization, administrative system and relationship between life on and off the job ${ }^{[2]}$. QWL consists of opportunities for active involvement in group working arrangements or problem solving that are of mutual benefit to employees or employers, based on labormanagement cooperation. People also conceive of QWL as a set of methods, such as autonomous work groups, job enrichment, high-involvement aimed at boosting the satisfaction and productivity of workers ${ }^{[3]}$. It requires employee commitment to the organization and an environment in which this commitment can flourish ${ }^{[4]}$. Thus, QWL is a comprehensive construct that includes an individual's job related well-being and the extent to which work experiences are rewarding, fulfilling and devoid of stress and other negative personal consequences ${ }^{[5]}$.

Accordingly, the rising number of two-income households is heightening the concern for employees' quality of work life. Given that female participation at work is increasing, it is apparent that males and females independently will need to take care of both work and home. Therefore, quality of work experience rather than work per se became the focus of attention ${ }^{[6]}$ and workplace wellness is crucial in promoting healthier working environments ${ }^{[7]}$.
In fact, Malaysia's industrial growth has created a high demand for labor in the manufacturing sector. Malaysia's electrical and electronics (E\&E) industry is the largest contributor to the country's manufacturing output, employment and exports. The E\&E industry continues to be Malaysia's largest export earner at $65.5 \%$ during the first six months of the year $2003^{[8]}$. Hence, the E\&E industry creates the largest number of job opportunities, totaling 20,493 in 2002 in the manufacturing projects out of the total of $68,575^{[9]}$. Due to the importance of this industry, it is a necessity to evaluate the working environment of the executives in this sector that require medium to high skills. Moreover, the Malaysian government is particularly keen to seek investment projects which will contribute substantially to technology advancement in areas of automation, digitalization, multimedia applications, consumer and industrial electronics. This is consistent with the finding that competition in world markets for products in electronics has increased considerably over the past few years. If this trend continues, this sector will become even more competitive in the years to come $^{[10]}$.

In summary, the limitations of individual job satisfaction had been pointed out in the literature for assessing the QWL and there had been no attempt in the past to measure QWL in terms of career aspects and organizational climate. This study is an attempt in such endeavor to further develop theoretical underpinnings to the available literature on QWL.

Past research on QWL: The evolution of QWL began in late 1960s emphasizing the human dimensions of work by focusing on the quality of the relationship between the worker and the working environment.

Corresponding Author: $\quad$ LooSee Beh, Faculty of Economics and Administration, Department of Administrative Studies and Politics, University of Malaya, Malaysia 
QWL as a discipline began in the U.S. in September 1972 when the phrase was coined at a "democratization of work" conference held at Columbia University's Arden House to discuss two movements. The first was a political movement inWestern Europe called 'Industrial Democracy'. Militant, socialist labor unions were lobbying the parliaments and assemblies of England, France, West Germany, Sweden and Italy to legislate worker participation in corporate decision-making. The second movement was the emergence in the U.S. of a number of social science theories about "humanizing the workplace" ${ }^{[11]}$. This shows that the model that evolved during the early years called for formalizing labor-management cooperation at the workplace by establishing joint committees at various levels to define, diagnose and devise solutions to day-to-day work problems. For instance, participation programs emerged from contract bargaining between General Motors Corporation and United Auto Workers Union was called Quality of Work Life in 1973 which was aimed at increasing workers' satisfaction with their jobs by giving them more information and a voice in decisionmaking ${ }^{[12]}$.

Indeed, it is difficult to best conceptualize the quality of work life elements ${ }^{[13]}$. Walton ${ }^{[4]}$ proposed eight major conceptual categories relating to QWL as (1) adequate and fair compensation, (2) safe and healthy working conditions, (3) immediate opportunity to use and develop human capacities, (4) opportunity for continued growth and security, (5) social integration in the work organization, (6) constitutionalism in the work organization, (7) work and total life space and (8) social relevance of work life.

Several published works have addressed the constructs that make up the QWL domain and key elements of QWL programs ${ }^{[1-5,14]}$. Others such as Pelsma et al. ${ }^{[15]}$ and Hart ${ }^{[16]}$ found that psychological distress and morale contributed equally to teachers' QWL. They determined that in the work climate of an occupation, QWL can be assessed by combining the amount and the degree of stress and the degree of satisfaction experienced by the individual within his/her occupational role. Winter et al. ${ }^{[17]}$ viewed QWL for academicians as an attitudinal response to the prevailing work environment and posited five work environment domains that include role stress, job characteristics, supervisory, structural and sectoral characteristics to directly and indirectly shape academicians' experiences, attitudes and behavior.

According to Loscocco and Roschelle ${ }^{[14]}$, the most common assessment of QWL is the individual attitudes. This is because individual work attitudes are important indicators of QWL. The ways that people respond to their jobs have consequences for their personal happiness, the effectiveness of their work organizations and even the stability of society. Individuals selectively perceive and make attributions about their jobs in accordance with the expectations they bring to the workplace. While the characteristics of the jobs have long been considered to be important influences on work attitudes, the past decades of 1970s and 1980s have witnessed much greater attention to aspects of the organizational context in which the job is performed. Thus, we must also look at how organizational characteristics exert both direct and indirect effect on the QWL.

Age may be the most commonly studied individual influence on work attitudes. Studies which use widely differing samples find consistent results: older employees are more satisfied, more job-involved and more committed to their work. Studies of the relation between career stage and job satisfaction and job involvement yield inconsistent findings. For example, there is a positive relation between career stage and work commitment when career stage is defined in terms of age, but curvilinear relations appear when age is defined in terms of job or company tenure ${ }^{[14]}$.

Past studies indicate that family roles reflect needs, opportunities and constraints have influence on individuals' reactions to work. After all, two important focal points of adult life are family and work. The role expectations of these two domains are not always compatible thus creating conflicts ${ }^{[18]}$. These conflicts are related to outcomes such as job dissatisfaction, job burnout and turnover ${ }^{[19-21]}$, as well as to outcomes related to psychological distress e.g. depression and life and marital dissatisfaction ${ }^{[22-24]}$. Work-family conflict studies have contributed to a better understanding of role conflict and its impact on mental health and the quality of work life ${ }^{[25]}$.

Career and QWL: A career is the evolving sequence of a person's work experiences over time. Career arises from the interaction of individuals with organizations and society. Career is not a primarily a theoretical construct but is used in meaningful ways, given meaning and it creates meaning and also experience. More specifically, career is referred to as a succession of related jobs, arranged in a hierarchy of prestige, through which persons move in an ordered, predictable sequence. There is also another side of career which linked to the individual's "moving perspective" on their life and its meaning.

Career satisfaction is defined as the satisfaction individuals derive from intrinsic and extrinsic aspects of their careers, including pay, advancement and developmental opportunities ${ }^{[26]}$. This is in contrast to job satisfaction defined as pleasurable or positive emotional state resulting from an appraisal of one's job or job experiences. Korman et al. ${ }^{[27]}$ developed a construct called materialistic ethic. It states that a career is more satisfying if it is higher in prestige, income and power in comparison to other positions. It can be said that career satisfaction is largely a matter of an individual comparing his/her career and life expectations with those being offered. In shaping such 
career expectations, there are economic considerations (e.g. compensation and retirement benefits) and occupational and family considerations (professional satisfaction, job satisfaction, advancement opportunities, relocation, etc.). Pay and perceived promotion opportunities are important determinants of career satisfaction in economic considerations. Organizational characteristics such as organizational emphasis on human resources, fairness of practices and policies regarding living conditions and family issues were also important. Family life includes support from spouse and personal flexibility which had been found to be an important determinant of career satisfaction ${ }^{[28]}$. As individuals reached their maturity stage of their careers, they have been found to place a greater emphasis on a balance between their work and family lives that individuals place on their family role as they age, the career satisfaction of older individuals is likely to be more negatively affected by work-family conflict than that of younger individuals. Some research indicates that a happy family life correlates with high levels of job satisfaction and objective career success $^{[29]}$. Rapoport and Rapoport ${ }^{[30]}$ supported this by showing that the family's morale support and the diversion that it entails make it an important factor affecting QWL.

Based on Judge et al. ${ }^{[31]}$, career success/achievement is defined as the positive psychological outcomes or achievements one has accumulated as a result of experiences over the span of working life which consists of objective career success (job title, salary or promotion) and subjective career success (one's own appraisal of career attainment). Research also suggests that job tenure and total time in one's occupation are positively related to career success/achievement besides the number of hours worked per week and salary and ascendancy ${ }^{[32]}$. A positive relationship between ambition and career success has been found in several studies of managers and executives ${ }^{[32,33]}$.

In respect to career balance, Herriot ${ }^{[34]}$ recognizes that sometimes there is a conflict between personal life and work and differences in perceptions of success in life. Two important focal points of adult life are family and work. Nevertheless, the role expectations of these two domains are not always compatible, creating conflicts between work and family life ${ }^{[18]}$. Due to the conflicting roles between work and family and commitment, it is hypothesized that a higher conflict in the work role will result in the lower quality of family life, meaning that a higher conflict will result in the lower level of QWL, in other words, having a balance between work and family will result in the higher level of QWL.

Propositions: With justification from the literature, it is reasonable to suggest that aspects of career development with reference to career satisfaction and career achievement are factors likely to have impact on QWL. Likewise, career balance with the rising indication of conflict between work and family life is also proposed as another factor determining QWL.

The key elements in QWL include decision participation, restructuring the nature of the work, enhancing the work environment and defining the reward structure. As pointed out in the literature, QWL reflects a concern for people's experience at work, their relationship with other people, their work setting and their effectiveness on the job ${ }^{[35]}$. QWL activity involves improvements in the workplace, with particular emphasis on physical work and the circumstances surrounding it. So, changes in rules, conditions, hours and other aspects of the environment are at issue. Reward system is essential in promoting a climate of involvement and career satisfaction. By mutually solving work-related problems, building cooperation, improving work environments, restructuring tasks and carefully and fairly managing human resource outcomes and payoffs, QWL programs will benefit both labor and management.

Research method: This study employed the survey method that allow for broad coverage, flexibility and convenience with inputs on related populations or events. Collection of data was self-administered to determine the level of QWL. Participation was granted through prior appointments and consent via phone calls from the organization. Each organization was visited at least twice by the researcher to establish rapport and reinforce contacts with the top management and related personnel to ensure smooth implementation of the questionnaire distribution and collection. A third visit was made to ensure a degree of interest and commitment on the part of the respondents to collect the questionnaires if data collection was not possible the second round, in addition to follow-up appeal via phone calls. Questionnaires that are not received after the fourth week were classified as non-respondents.

Instrument development: Since this research is not a replication of any previous studies, the questionnaire was developed through literature review and a mix and match approach was undertaken to modify the sentence or complete withdrawal wherever necessary to suit the local context.

While academics assisted in assessing face validity, the managerial professionals in a multinational corporation verified content validity. The final questionnaire was pre-tested on 19 managers. The coefficient values were all above 0.8 , thus meeting Nunnally's $^{[36]}$ recommendation of $>0.7$ as the acceptable reliability level. The overall alpha value was .8768. The final questionnaire had a total of 73 items measuring six constructs (five independent and one dependent). 
Response scale: A ten-point scale with 1 being "strongly disagree" and being 10 "strongly agree" was used. The type of statistical analysis required for this study (i.e. multiple regression analysis) dictated the use of an interval scale, one which guaranteed that the distances between adjacent numbers were the same and had no true zero ${ }^{[37]}$. Therefore, the anchors of scale points were limited to the extremes without having any between. As advised by Allen and $\mathrm{Rao}^{[38]}$, calculating means and standard deviations are "highly suspect" if ordinal-level scales are used. Typically, it is easier to give ratings in terms of percentages or points e.g. 80 per cent or 80 points. The simplicity of a 10-point scale is preferred as compared to the scale of any other number ( 5 or 7 ) that may need more explanations. Further, for a narrow scale there are low levels of intercorrelation and limited variance ${ }^{[38,39]}$. This was particularly important, with variance explanation being the main concern for this study.

Target population and sample: A stratified random sampling procedure was employed. The selection of respondents using this technique involves a complete list of industrial firms, multinationals (MNCs) and small-medium industries (SMIs). A total of 475 respondents as a good representative of the target population of approximately 3,500 executives was reached over a three-month period. The sample consists of executives from the hub of industrial free trade zones in the Klang Valley near Kuala Lumpur, in the prime areas of the location of the $\mathrm{E} \& \mathrm{E}$ industry where many of the MNCs as well as the SMIs are situated and is accessible.

Data analysis: The quantitative data collected was subjected to various statistical analyses. Stepwise regression, a method by which each predictor variable is selected for inclusion in the model based on the significance of $t$-statistics in a step-by-step selection, was chosen based on the premise that multicollinearity, which is a common problem in multiple regression, could be somewhat circumvented ${ }^{[38]}$. In this study, a default $\alpha$ of 0.05 was used to determine the level of significance. Table 1 contains summary statistics, Cronbach's alphas and zero-order correlation matrix for the variables under study.

\section{RESULTS}

In total, the final number collected was 480 of which 5 were not used as their designation positions were not from the sampling requirements as they were non-executives. Hence, the final usable sample was reduced to 475 which had a returned rate of $83.6 \%$. By and large, it was felt that the samples were representative of the populations for the respective areas studied.
Of the respondents, 67.2 per cent were male and 32.8 per cent were female. The majority of the respondents were aged 30-39 years (49.7\%), followed by $40-49$ years $(23.8 \%), 24-30$ years $(21.9 \%)$ and $>50$ years $(4.6 \%)$. The average age is 36.33 years $(\underline{\mathrm{SD}}=6.905)$ with the youngest 24 years and oldest 58 years. The majority was married $(77.5 \%)$, followed by singles $(20.4 \%)$, divorced/separated $(0.8 \%)$ and living with partner $(0.8 \%)$. The majority has bachelors degree $(49.7 \%)$, diploma $(30.1 \%)$, professional degree $(10.9 \%)$, masters degree $(8.2 \%)$ and certificate level (1.1\%). $44.2 \%$ of the respondents had less than 10 years of total tenure employment, followed by $43.6 \%$ (11-20 years), $11.2 \% \quad(21-30 \quad$ years $)$ and $1.1 \% \quad(>30$ years).They had worked an average of 12.5 years $(\underline{S D}=6.9639)$ in their career with a minimum of 3 months and a maximum of 37 years with an average tenure of 9.2 years $(\underline{S D}=6.116)$ with a minimum of 3 months and a maximum of 32 years with the current employer.

Level of QWL: Based on the ten-point scale used, the minimum QWL rating was 2.30 and a maximum of 10.00 and this gives a range of 7.70. The median QWL rating value was 6.40 with a standard deviation of 1.46. The mean QWL rating was 6.39 implying that overall the level of QWL is good.

The $25^{\text {th }}$ percentile of the QWL is 5.40 and the $75^{\text {th }}$ percentile is 7.40 and thus the interquartile range (IQR) is 2.00 . The values obtained for the $25^{\text {th }}$ and $75^{\text {th }}$ percentile suggest that $50 \%$ of the respondents have a QWL rating between 5.40 and 7.40. The $90^{\text {th }}$ percentile of the QWL is 8.24 , which mean that $90 \%$ of the respondents have a QWL reading of 8.24 or less. In other words, only $10 \%$ of respondents obtained a QWL reading of above 8.24.

In accordance with the ratings of below 4 is low, 46 is moderate, $7-8$ is good and above 8 is excellent as the indication of satisfaction, the executives appeared to have been rather satisfied with their level of QWL. The executives who felt that their level of QWL is good $(49.5 \%)$, moderate $(30.7 \%)$, excellent $(13.1 \%)$ and low $(6.1 \%)$.

The findings in Table 1 indicate that the mean ratings for the independent variables in descending order of high to low are career achievement $(\mathrm{M}=6.6766$, $\underline{\mathrm{SD}}=1.4123), \quad$ career $\quad$ satisfaction $\quad(\underline{\mathrm{M}}=6.3905$, $\underline{\mathrm{SD}}=1.1148)$ and career balance $(\underline{\mathrm{M}}=5.6749$, $\underline{\mathrm{SD}}=1.1499)$.

As depicted in Table 1, QWL is positively related to career satisfaction $(\mathrm{r}=.599, \mathrm{p}=0.001)$, career achievement $(\mathrm{r}=.711, \mathrm{p}=.001)$, career balance $(\mathrm{r}=$ $.143, \mathrm{p}=.001)$.

Determinants of QWL: To find out the determinants of QWL, a stepwise regression method was used. Based on the stepwise method used, the three predictor variables were found to be of significance in explaining 
Table 1: Descriptive Statistics, zero-order correlations and Cronbach's alpha of QWL and the predictor variables

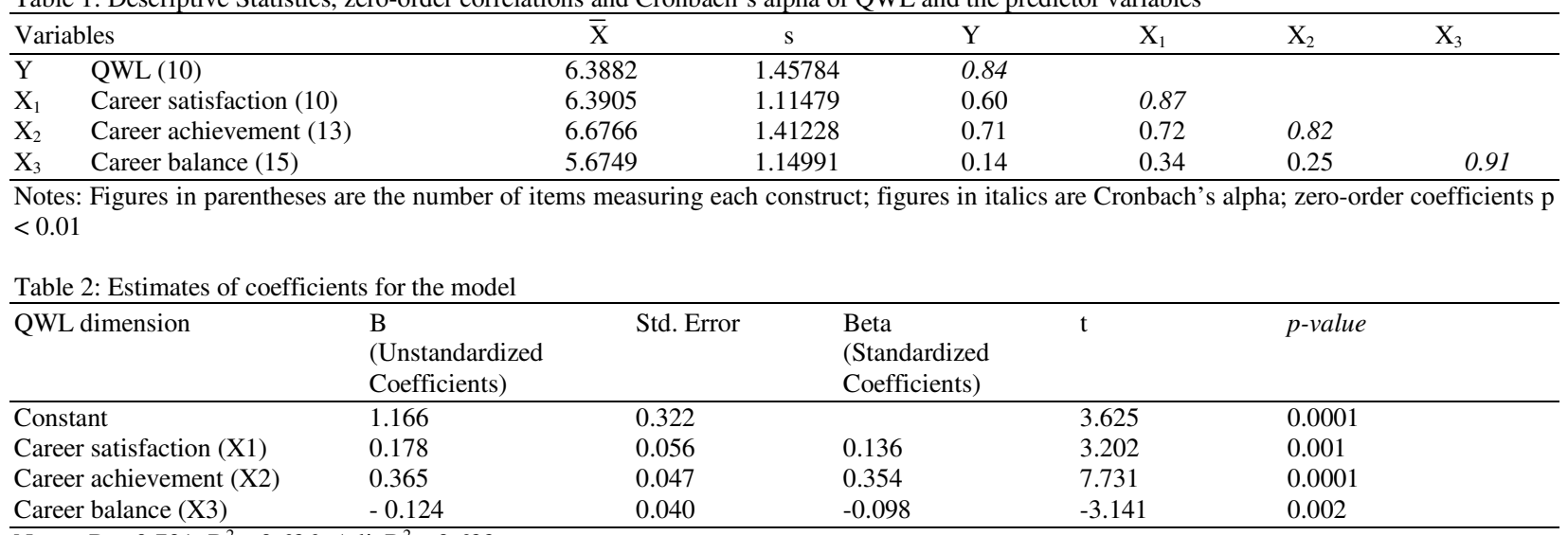

Notes: $\mathrm{R}=0.791 ; \mathrm{R}^{2}=0.626 ;$ Adj. $\mathrm{R}^{2}=0.622$

QWL. The three predictor variables are career satisfaction, career achievement and career balance .

As depicted in the coefficients table (Table 2), the estimates of the model coefficients for $\beta_{0}$ is $1.166, \beta_{1}$ is $0.178, \beta_{2}$ is $0.365, \beta_{3}$ is - 0.124. Therefore, the estimated model is as below:

$\mathrm{Y}(\mathrm{QWL})=1.166+0.178\left(\mathrm{X}_{1}\right)+0.365\left(\mathrm{X}_{2}\right)-0.124$ $\left(\mathrm{X}_{3}\right)+E$

Where:

$\mathrm{X}_{1}=$ career satisfaction,

$\mathrm{X}_{2}=$ career achievement,

$\mathrm{X}_{3}=$ career balance and

The R-squared of 0.626 implies that the four predictor variables explain about $62.6 \%$ of the variance in the QWL. This is quite a respectable result. The ANOVA table revealed that the F-statistics (157.126) is very large and the corresponding p-value is highly significant $(0.0001)$ or lower than the alpha value of 0.05 . This indicates that the slope of the estimated linear regression model line is not equal to zero confirming that there is linear relationship between QWL and the predictor variables.

As depicted in Table 2, the Beta value for career achievement is the highest (0.354), followed by career satisfaction (0.136). The Beta value for career balance is the smallest $(-0.098)$ indicating that it made the least contribution.

Based on the collinearity diagnostic table obtained, none of the model dimensions has condition index above the threshold value of 30.0, none of tolerance value smaller than 0.10 and VIF statistics are less than 10.0. This indicated that there is no serious multicollinearity problem among the predictor variables of the model. The normal P-P plot of regression standardized residuals revealed all observed values fall roughly along the straight line indicating that the residuals are from a normally distributed. The scatterplot (standardized predicted values against observed values) indicate the relationship between the dependent variables and the predictors is linear and the residuals variances are equal or constant. Since there is no multicollinearity problem between the predictors included in the model and the assumptions of normality, equality of variance and linearity are all met, hence, it is reasonable to conclude that the estimated multiple regression model is valid and quite respectable.

\section{DISCUSSION}

Without doubt, the most important determinant of QWL is career achievement, followed by career satisfaction and career balance.

Marital status, age, income, education, total tenure years of employment and tenure with current employer correlate positively with QWL. In this sample, this indicates that as age increases, so does the level of career achievement. Similarly with the increase of the total tenure years of employment and tenure with the current employer also indicate the increase in the level of QWL. Accordingly, the number of children correlates negatively with total tenure years of employment, career satisfaction, career achievement, organizational climate and QWL. This means that as age increases, together with the total tenure years of employment and with the current employer, the number of children decreased. In turn, this will increase the level of career satisfaction, career achievement and QWL. This is consistent with the literature that age positively predicts success presumably because extrinsic outcomes accrue over time ${ }^{[40,41]}$. It also indicates that older respondents had been long in their career and had achieved more promotions in their careers than had younger executives ${ }^{[31]}$. Also, the respondents who worked in MNCs were reported to have a slightly higher level of QWL as compared to those in SMIs. The higher the income obtained by the respondents, the higher the level of QWL.

However, the respondents did not express the level of satisfaction with their career balance. This is in line with the literature standpoint and expressed in the conflict between work and family life. The results show 
that the respondents are satisfied with their achievement $(63.8 \%)$ in their career progress but not in terms of career balance $(36.6 \%)$. Participation in the work (family) role is made more difficult by virtue of participation in the family (work) role ${ }^{[22]}$. Executives who value their career quite highly will find that it affects the amount of time they can devote to the family ${ }^{[41]}$. Rapoport and Rapoport ${ }^{[30]}$ supported this by showing that the family's morale support and the diversion that it entails make it an important factor affecting QWL.

There is significant difference of QWL between married and singles $(\mathrm{F}=1.644$, df $=463, \mathrm{p}=0.02)$. Those who are married and have children have a higher level of QWL as compared to the singles. Past researchers have observed that in early stages of their careers, individuals are often willing to sacrifice their personal lives in the interests of their career progression. However, as individuals advance in age to the maturity stage of their career, they have been found to place a greater emphasis on a balance between their work and family lives that individuals place on their family role as they age. Prior research has found that being married leads individuals to give their personal lives priority over their work lives. Similarly, being a parent increases the importance that individuals place on their family role. Some research indicates that a happy family life correlates with high levels of job satisfaction and objective career success ${ }^{[29]}$. This is supported in this sample of study.

In this study, the $\mathrm{E} \& \mathrm{E}$ industry comprises mostly Japanese companies where the workers tend to have higher work centrality and place a greater emphasis on job security and stability even though they are Malaysians. This finding is in accordance with Lundberg and Peterson $^{[42]}$ and England and Misumi ${ }^{[43]}$. This suggests that Japanese have instituted similar cultures in Malaysia and even perhaps that our Malaysian culture, may be more attracted to traditional careers with an average tenure of 9.2 years with the current employer and in contrast to the boundaryless career concept that capture the working lives of Americans more accurately.

Implications: The result of this study supports the proposition that the degree of satisfaction in QWL is related to the degree to which the individual believes his or her success criteria have been met, especially if the individual places great importance on these criteria which include pay, respect, personal growth and family life balance. This supports the materialistic work ethic that place strong emphasis on corporate power, income and personal growth as parts of their careers. It can also be concluded from the data, that the individual's family life correlates significantly with his/her level of QWL. This further suggests that a successful family life carries over into one's career and makes one more satisfied with personal achievements.
The fact that is worthy of conclusion is the importance of career achievement in QWL. In the current context, the emphasis is on income, position and personal growth and opportunity in career mobility as potential success indicators. Further, this is related to having a harmonious successful home environment from spousal and family support that is highly valued where career balance is expected to provide some impact as found in this paper.

It can thus be concluded that the essential determinants of QWL appears to be career related, taking into account the executives' met expectations of their career development.

Some suggestions for future research: This study has the potential value for further research. To ensure representativeness, the study should be replicated to cover a bigger sampling frame and the results should be compared to those found in this study. Future research should further explore the perception of career and understand that changes may take place in that perception as life events occur and how social values relate to career elements and family elements if we are to increase our present limited ability to explain individual's QWL. Given the changes experienced by organizations that can include the virtual organizations and telecommuting, one possible insight is to evaluate the extent of QWL and the desirable level in such postmodern climate where flexibility into organizational structures and work schedules are emerging.

\section{REFERENCES}

1. Straw, R.J. and C.C. Heckscher, 1984. QWL: New working relationships in the communication industry. Labor Studies J., 9: 261-274.

2. Cunningham, J.B. and T. Eberle, 1990. A guide to job enrichment and redesign. Personnel, 67: 56-61.

3. Feuer, D., 1989. Quality of work life: a cure for all ills? Training: The Magazine of Human Resources Development, 26: 65-66.

4. Walton, R.E., 1975. Criteria for Quality of Working Life. In L.E. Davis, A.B. Cherns and Associates (Eds.) The Quality of Working. New York: The Free Press, Life, 1: 91-104

5. Shamir, B. and I. Salomon, 1985. Work-at-home and the quality of working life. Acad. Manag., 10: 455-464.

6. Lewis, S. and C.L. Cooper, 1999. The work-family research agenda in changing contexts. J. Occupat. Health Psychol., 4: 382-393.

7. Offerman, L.R. and M.K. Gowing, 1990. Organizations of the future: changes and challenges. Am. Psychologist, 45: 95-108.

8. Ministry of Finance Malaysia, 2003. Economic Report 2003/2004. Kuala Lumpur: PNMB.

9. MIDA Report, 2003. Retrieved June 11, 2003. http://www.mida.org/stats_report.html. 
10. Akyüz, Y., 2003. Developing countries and world trade: performance and prospects. Geneva, Switzerland: UNCTAD.

11. Davenport, J., 1983. Whatever happened to QWL? Office Administration and Automation, 44: 26-28.

12. Smith, D.C., 1983. QWL, EI needed now more than ever. Ward's Auto World, 19, 12.

13. Seashore, S.E., 1975. Defining and measuring the quality of working life. In L.E. Davis and A.B. Cherns (Eds.), The quality of working life, New York: The Free Press, pp: 105-118.

14. Loscocco, K.A. and A.R. Roschelle, 1991. Influences on the quality of work and non-work life: two decades in review. J. Vocational Behavior, 39: 182-225.

15. Pelsma, D.M., G.V. Richard, R.G. Harrington and J.M. Burry, 1989. The quality of teacher work life survey: a measure of teacher stress and job satisfaction. Measurement and Evaluation in Counseling and Development, 21: 165-176.

16. Hart, P.M., 1994. Teacher quality of work life: integrating work experiences, psychological distress and morale. J. Occupat. Organ. Psychol., 67: 109-132.

17. Winter, R., T. Taylor and J. Sarros, 2000. Trouble at mill: quality of academic worklife issues within a comprehensive Australian university. Studies in Higher Education, 25: 279-294.

18. Netemeyer, R.G., J.S. Boles and R. McMurrian, 1996. Development and validation of work-family conflict and family-work conflict scales. J. Appl. Psychol., 81: 400-410.

19. Burke, R.J., 1988. Some antecedents and consequences of work-family conflict. J. Social Behavior and Personality, 3: 287-302.

20. Frone, M.R., M. Russell and M.L. Cooper, 1992. Antecedents and outcomes of work-family conflict: Testing a model of the work-family interface. J. Appl. Psychol., 77: 65-78.

21. Pleck, J.H., L.S. Graham and L. Linda, 1980. Conflicts between work and family life. Monthly Labor Review, 103: 29-33.

22. Greenhaus, J.H. and N.J. Beutell, 1985. Sources of conflict between work and family roles. Acad. Manag. Rev., 10: 76-88.

23. Gutek, B.A., S. Searle and L. Klepa, 1991. Rational versus gender role expectations for workfamily conflict. J. Appl. Psychol., 76: 560-568.

24. Voydanoff, P., 1988. Work role characteristics, family structure demands and work/family conflict. J. Marriage and the Family, 50: 749-761.

25. Higgins, C., L. Duxbury and R.H. Irving, 1992. Work-family conflict in the dual-career family. Organizational Behavior and Human Decision Processes, 51: 51-75.

26. Greenhaus, J.H., S. Parasuraman and W.M. Wormley, 1990. Effects of race on organizational experiences, job performance evaluations and career outcomes. Acad. Manag. J., 16: 129-137.
27. Korman, A.K., S.R. Mahler and K.A. Omran, 1983. Work ethics and satisfaction, alienation and other reactions. In W.B. Walsh and S.H. Osipow (Eds.), Handbook of Vocational Psychology, 2: 181-206. Hillsdale, New Jersey: The Free Press.

28. Stroh, L., J. Brett and A. Reilly, 1996. Family structure, glass ceiling and traditional explanations for the differential rate of turnover of female and male managers. J. Vocational Behavior, 49: 99118.

29. Shaffer, G.S., 1987. Patterns of work and non-work satisfaction. J. Appl. Psychol., 72: 115-124.

30. Rapoport, R. and R.N. Rapoport, 1980. Balancing work, family and leisure: a triple helix model. In C.B. Derr (Ed.). Work, family and the career. New York: Praeger.

31. Judge, T., D. Cable, J. Boudreau and R. Bretz, 1995. An empirical investigation of the predictors of executive career success. Personnel Psychology, 48: 485-519.

32. Cox, C.J. and C.L. Cooper, 1989. The making of the British CEO: Childhood, work experience, personality and management style. Acad. Manag. Executive, 3: 241-245.

33. Cannings, K. and C. Monmarquette, 1991. Managerial momentum: a simultaneous model of the career progress of male and female managers. Industrial and Labor Relations Review, 44: 212228.

34. Herriot, P., 1992. The career management challenge. London: Sage.

35. Chan, C.H. and W.O. Einstein, 1990. Quality of Work Life (QWL): What can unions do? SAM Advanced Management J., 55: 17-22.

36. Nunnally, J.C., 1978. Psychometric Theory. 2nd Edn. New York, NY: McGraw-Hill.

37. Sapsford, R., 1999. Survey research. Thousand Oaks, CA: Sage Publications.

38. Allen, D.R. and T.R. Rao, 2000. Analysis of customer satisfaction data. Milwaukee, WI: ASQ Quality Press.

39. Sekaran, U., 2000. Research Methods for Business: A skill-building approach, $3^{\text {rd }}$ ed. New York, NY: Wiley.

40. Cox, T.H. and S.M. Nkomo, 1991. A race and gender-group analysis of the early career experience of MBAs. Work and Occupations, 18: 431-446.

41. Gattiker, U.E. and L. Larwood, 1990. Predictors for career achievement in the corporate hierarchy. Human Relations, 43: 703-726.

42. Lundberg, C.D. and M.F. Peterson, 1994. The meaning of working in the U.S. and Japanese local governments at three different hierarchical levels. Human Relations, 47: 1459-1487.

43. England, P. and J. Misumi, 1986. Work centrality in Japan and the United States. J. Cross-Cultural Psychol., 17: 399-416. 